\title{
The Journal of Social Sciences Research
}

ISSN(e): 2411-9458, ISSN(p): 2413-6670

Vol. 6, Issue. 8, pp: 804-810, 2020

URL: https://arpgweb.com/journal/journal/7

DOI: https://doi.org/10.32861/jssr.68.804.810

\section{Social Media Use and Political Polarization: Political Engagement as a Mediator}

\section{Kinza Amjad}

Department of Media and Communication, University of Management and Technology, Lahore, Pakistan

\section{Muzammil Saeed}

Department of Media and Communication, University of Management and Technology, Lahore, Pakistan

\section{Farahat Ali}

Faculty of Media and Communication Studies, University of Central Punjab, Lahore, Pakistan

Muhammad Awais (Corresponding Author)

Department of Media and Communication, University of Management and Technology, Sialkot Campus, Pakistan Email: muhammad.awais@skt.umt.edu.pk

\author{
Article History \\ Received: July 20, 2020 \\ Revised: August 24, 2020 \\ Accepted: August 28, 2020 \\ Published: August 31, 2020 \\ Copyright (C) 2020 ARPG \& \\ Author \\ This work is licensed under \\ the Creative Commons \\ Attribution International

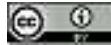 \\ CC BY: Creative \\ Commons Attribution \\ License 4.0
}

\begin{abstract}
Social media, in the new millennium, has become a very effective tool of communication, information, and propagation regarding all social, religious, and political discourses that further lead towards ideological divisions. In the contemporary democratic world, the role of social media for political opinion building is obvious which is done by opinion leaders through political information and debates. The purpose of this study is to explore the social media use and political polarization among social media users. The survey research method was used to examine social media use for political engagement and political polarization. Private university students were selected as participants $(n=350)$. The result was found positive which means that social media use is responsible for political polarization. Moreover, social media use is also a significant predictor of political engagement. In addition to this, the results show that political engagement is a mediator between the relationship between social media use and political polarization. The practical implications of the study have been discussed.
\end{abstract}

Keywords: Social media; Political participation political engagement; Political polarization.

\section{Introduction}

Social media use which is reaching its peak among adults of the developed world for participation in digital political spheres (Correa et al., 2010) has become the part and parcel of the life of urban citizens of developing world for political engagement (Poushter et al., 2018), and this new political behavior has accelerated the process of political communication engaging participants in commenting and sharing of political content (Cherubini and Nielsen, 2016). In the 2018 elections of Pakistan, a tremendous surge was found in the use of social media due to its polyvocality; all leading political parties, renowned and active candidates, political workers, and even the supporters exploited this ubiquitous source of communication, particularly Facebook and Twitter, to achieve their goals. They not only propagated the agendas and manifesto of their parties but also lead campaigns against the opponents by criticizing their political and personal offenses (Jarral, 2018).

This behavior generates fabricated content on social media platforms (Gentzkow and Shapiro, 2011), and people expose to biased information (Sunstein, 2001) because they prefer the contents which support their pre-existing views, and usually accept information which is favorable to their views while analyzing the other side with preferential approach (Hart and Nisbet, 2012). Resultantly, participants inhale more biased information as compared to past when people's opinion polarization may depend on more accurate information regarding political issues (Hastorf and Cantril, 1954; Taber and Lodge, 2006), and these online forums have the potential to increase the partisan polarization which is the main root for establishing individual opinion, criticism on different political parties and uncivil conversation (Levendusky and Malhotra, 2016). Social media is considered highly responsible for the polarization of the audience's opinion regarding the issues of politics which leads towards political polarization (Lelkes and Westwood, 2017) which is resulted mainly through online political discussions (Sunstein, 2001). This study has attempted to explain the relationship between social media use and political polarization by examining adults' political engagement on Facebook and Twitter.

The relationship of social media use, political polarization, and political participation in university students have not yet been studied in our country where political institutions are still struggling for democracy. There are two types of studies already available on the same subject. The first type of studies have found that social media provides selective exposure and dividing the people into party lines and the results of these studies are mixed which means some consider social media role in political polarization (Barberá et al., 2015; Shin and Thorson, 2017) while others do not (Bakshy et al., 2015). The second type of study has found that political polarization normally occurs in the old age group and they are not frequent users of social media (Boxell et al., 2017). The current study will help to understand the effect of social media along with political engagement because it wasn't yet studied. The study will 
also help to understand the use of social media as a political polarizer and reason for being loyal to a party in an adult's life.

The use of social media for democratic and political discussions among adults is increasing at a great pace in this new millennium (Stieglitz and Dang-Xuan, 2012). Its participatory and interactive features have made it most attractive medium for political conversation, even, young people who are least interested in politics, social media grab their attention towards political issues and keep them engage them with different political groups and institutions. These social networking sites, particularly Facebook and Twitter, are providing a platform to the public for debating and critiquing (Aday et al., 2013; Farrell and Drezner, 2008). Twitter, with the politicians' millions of followers, is believed to spread the information not only to the general public but also to the political institutions (Lassen and Brown, 2011), however, use of Facebook to communicate with the general public for the dissemination of political messages and to keep them engaged in political discussion and manipulation is common among political officials (Williams and Gulati, 2009).

However, in this high-choice media environment participants mostly choose news and information congruent to their existing beliefs and avoid those oppose their viewpoint and ideology (Lee and Chan, 2016). Even, they manipulated the original content of mainstream media before sharing on their networks. This attitude significantly affects the public perception about political entities (Bennett and Segerberg, 2013), and develop a culture of biased opinion even against the opinion of their political leaders due to lack of communicative truthfulness which raises the opinion polarization among people (Lee and Chan, 2016). Empirical evidence on the role of social media in opinion polarization expressed that this process fabricates partisan individuals and leads towards partisan polarisation rather than popular polarization (Baldassarri and Bearman, 2007). The level of political partisanship and division is increasing in such a way that supporters of political parties often respond with illogical comments and sarcastic remarks towards opposing participants (Newport, 2019). Hostility is increasing among family members and friends, and this negative partisanship has become the grand drive force of hate motivation (Masih and Slater, 2019) because political leaders and candidates fan the flames as well by sharing hate speeches and images on mainstream and social media (Neyazi, 2020).

Several researchers argue that fragmentation of users on social media creates echo chambers where they receive one-sided probably biased news and information from like-minded participants (Boxell et al., 2017) while political polarization only occurs in the context of political discussions with the heterogeneous community (Tang, 2015). No doubt, social media platforms are highly responsible for political discussions (Lassen and Brown, 2011; Williams and Gulati, 2009), however, it is observed that most political activists and loyal workers are politically polarized due to their extreme position on political issues, though the public is not due to heterogeneity (Baldassarri and Bearman, 2007). Ordinary citizens generally receive political news and information by their friends and family members of different political networks and affiliations which expose them with different viewpoints and reduce political radicalism (Barberá, 2015). That is why social media is also considered helpful in reducing political polarization among the mass community.

We used the self-perception and cognitive dissonance theory to explain how social media use affects political participation and polarization. This study will provide a complete picture of the young generation who are indulged in using social media and have their political viewpoints about each Pakistani political party. Based on the above literature following objectives and hypotheses are formulated.

\subsection{Objectives}

The objectives of this study are to analyze the use of social media by young generation and it gives rise to certain points regarding politics which are as follows:

1. To examine the relationship between social media use and political polarization.

2. To examine the relationship between social media use and political engagement.

3. To examine the relationship between political polarization and political engagement.

4. To find out the mediation of political engagement between the relationship of social media use and political polarization.

\subsection{Hypotheses}

The study proposed the following alternative hypothesis for testing;

H1: Social media usage positively affects political polarization (party-based, leadership-based, and Issue-based polarization).

H2: Social media usage positively affects political engagement.

H3: Political engagement positively affects political polarization (party-based, leadership-based, and Issuebased polarization).

H4: Political engagement will mediate the relationship between social media use and political polarization (party-based polarization).

H5: Political engagement will mediate the relationship between social media use and political polarization (leadership-based polarization).

H6: Political engagement will mediate the relationship between social media use and political polarization (Issue-based polarization). 


\section{Material and Method}

In the present, a cross-sectional research design was used to collect the data because the data was collected from the research participants at a single point in time or during a single, relatively brief period. A cross-sectional research design involves the identifying relationship between two variables (Thatcher et al., 2011). The cross-sectional study provides a picture of the result and characteristics which are related to the results. It is descriptive and can be done in the form of a survey (Greenwood and Levin, 2006).

For collecting data, purposive sampling technique was used because in this technique, the sample was selected based on the characteristics of the population and it can be very useful in the situations when we need to reach a targeted sample quickly and where sampling for proportionality is not the main concern (Crossman, 2017). The sample size consisted of the 350 university students with the age range from 20-31. The students of every education level were included such as undergraduates, graduates, postgraduates, and even students with a professional degree was also examined.

\subsection{Measures}

The following scales were used regarding research variables for collecting data. The five-point rating scale was used to measure the time spent on social media for news purposes and this scale was developed by Lee (2016). The political engagement scale is adopted by Lee et al. (2018) study. The political polarization scale was adopted from the Matsuno (2013) study.

\subsection{Data Analysis}

SPSS version 25 was used for preliminary data analysis while Process Macro was used for mediation analysis.

\section{Results}

\subsection{Sample Description}

In this section of the study, the mean, standard deviation, frequencies, and percentage of demographic variables of the sample $(\mathrm{N}=350)$ participated in the current study will be described. The study was conducted on university students and the total sample was 350 students of private universities. The table described the frequencies and percentages of demographic variables of participants that showed the sample consisted of 350 university students' Demographic variables that were used in the study to define the characteristics included Gender, age, level of education, and locale. The mean age of university students are 20.25 that varies in the age ranges from 19-24. The present study is based on the participant's locale from where they belong which will help in examining their political opinions. As the participants were selected from Pakistan's private universities so it is important to investigate their locale which consists of two categories such as urban or rural. The participants belonged from urban were 234 $(64.6 \%)$ and rural were $118(32.9 \%)$. In the present study, education of a large group of university students as undergraduates and large group belonged to undergraduate level was $241(67.1 \%)$ whereas small group consisted of professional degree that was $13(3.6 \%)$, other groups were in the middle of both groups as graduates were 70 $(19.5 \%)$ and postgraduates were $26(7.2 \%)$.

Table-1. Demographic Characteristics of Sample (N=350)

\begin{tabular}{l|l|l}
\hline Variables & $\boldsymbol{f}$ & $\boldsymbol{\%}$ \\
\hline Gender & & \\
\hline Male & 261 & 72.7 \\
\hline Female & 89 & 24.8 \\
\hline Locale & & \\
\hline Rural & 118 & 32.9 \\
\hline Urban & 232 & 64.6 \\
\hline Level of Education & & \\
\hline Undergraduate & 241 & 67.1 \\
\hline Graduate & 70 & 19.5 \\
\hline Postgraduate & 26 & 7.2 \\
\hline Professional Degree & 13 & 3.6 \\
\hline Note: f= frequency and \%= percentage & &
\end{tabular}

Table 2 indicates that demographics include education and geographic representation was found to be positive predictors of political polarization in university students. Leader based polarization is a positive predictor of political polarization whereas other variables include social media, party-based polarization, issue-based polarization, and party loyalty are also a positive predictor of political polarization. Some control variables and demographics were found to have a significant relationship with the dependent variable but gender, age, and locale are predicted as negatively related to the SMU (social media use) which means that older individuals get less affected by social media and people who belong to different locale use social media according to their interests and knowledge. The model shows that control variables have an insignificant relationship with party-based and leadership-based polarization. Bur this relationship was significant with issue-based political polarization. In addition to this, social media use and political engagement have a significant effect on party-based, leadership-based, and issue-based 
political polarization. Overall variance explained by social media use and political engagement in party-based polarization was $32 \%$, leadership-based polarization $21 \%$, and $29 \%$ variance explained in issue-based polarization. Thus, $\mathrm{H} 1, \mathrm{H} 2$, and $\mathrm{H} 3$ are accepted.

Table-2. Hierarchical Regression Analysis Predicting Political Polarization ( $\mathrm{N}=350)$

\begin{tabular}{|c|c|c|c|c|}
\hline \multirow[b]{2}{*}{ Predictor } & \multicolumn{2}{|c|}{ Party-Based } & \multirow[t]{2}{*}{ Leadership-Based } & \multirow[t]{2}{*}{ Issue-Based } \\
\hline & $\Delta R^{2}$ & $\bar{\beta}$ & & \\
\hline Step 1 & .005 & & .009 & .034 \\
\hline \multicolumn{5}{|l|}{ Control Variables* } \\
\hline Step 2 & .31 & & .20 & .26 \\
\hline Social Media Usage & & $.54 * * *$ & $.27 * *$ & $.42 * *$ \\
\hline Political Engagement & & $.56 * *$ & $.29 * *$ & $.31 * *$ \\
\hline Total $R^{2}$ & & $.32 * *$ & $.21 * *$ & $.29 * *$ \\
\hline
\end{tabular}

Note: Control Variables $*$ gender, age, education, locale, residence, monthly income $* p<.05, * * p<.01, * * * \mathrm{p}<.001$

\subsection{Mediation Analysis}

Mediation analysis with the help of Process macro by Hayes was performed, and it was found that the direct effect of social media use with the Party-based Polarization was found to be significant and indirect effect was also significant. The relationship of social media use with party-based polarization was significantly mediated by political engagement. Thus, H4 is accepted.

Figure-1. Diagram of the mediation model with Regression Coefficients, direct and indirect effect

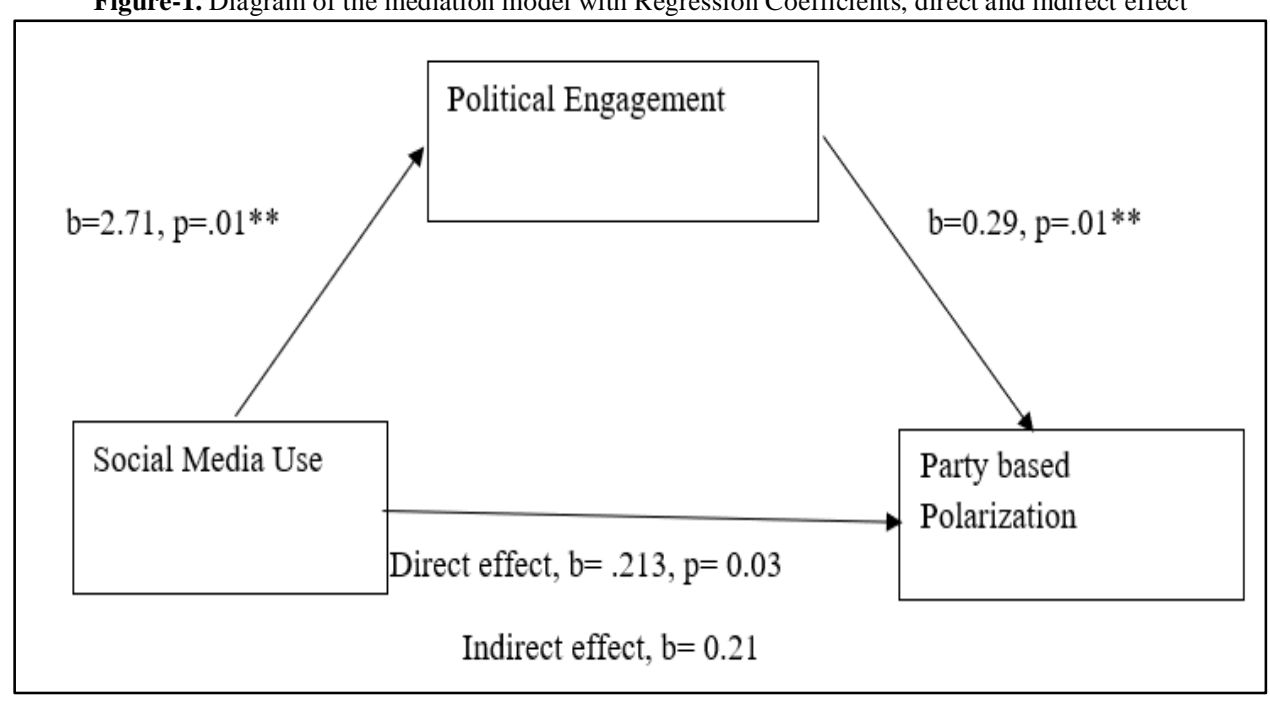

Mediation analysis with the help of Process macro by Hayes was performed, and it was found that the direct effect of social media uses on political engagement and political engagement effect on leader-based polarization was found to be significant and, in this examination, the indirect effect of social media use and leadership polarization was also found to be significant. Social media use and leadership-based polarization were mediated by political engagement. Therefore, H5 is accepted.

Figure-2. Diagram of the mediation model using other Variable with Regression Coefficients, direct and indirect effect

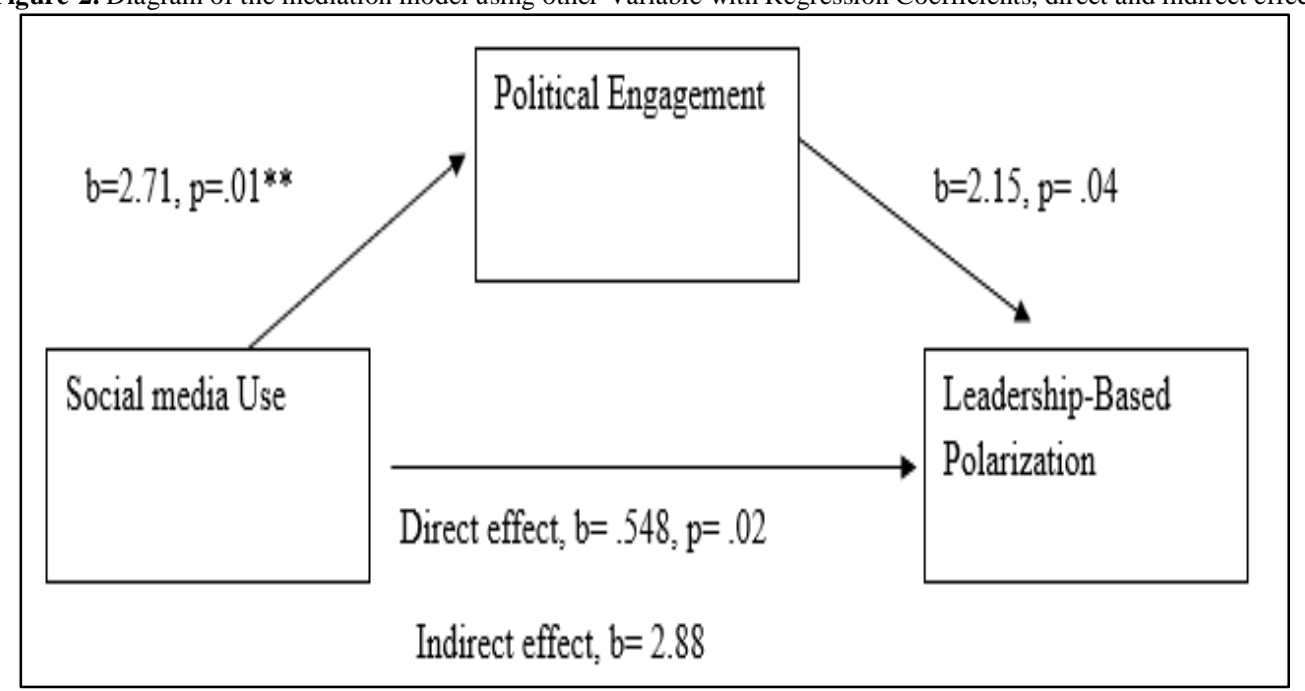


Mediation analysis with the help of Process macro by Hayes was performed, and it was found that all the direct effect was resulted as significant, and in this analysis, social media use and issue-based polarization was mediated by political engagement. Thus, H6 is accepted.

Figure-3. Diagram of the mediation model using issue-based polarization as the dependent variable with regression coefficients

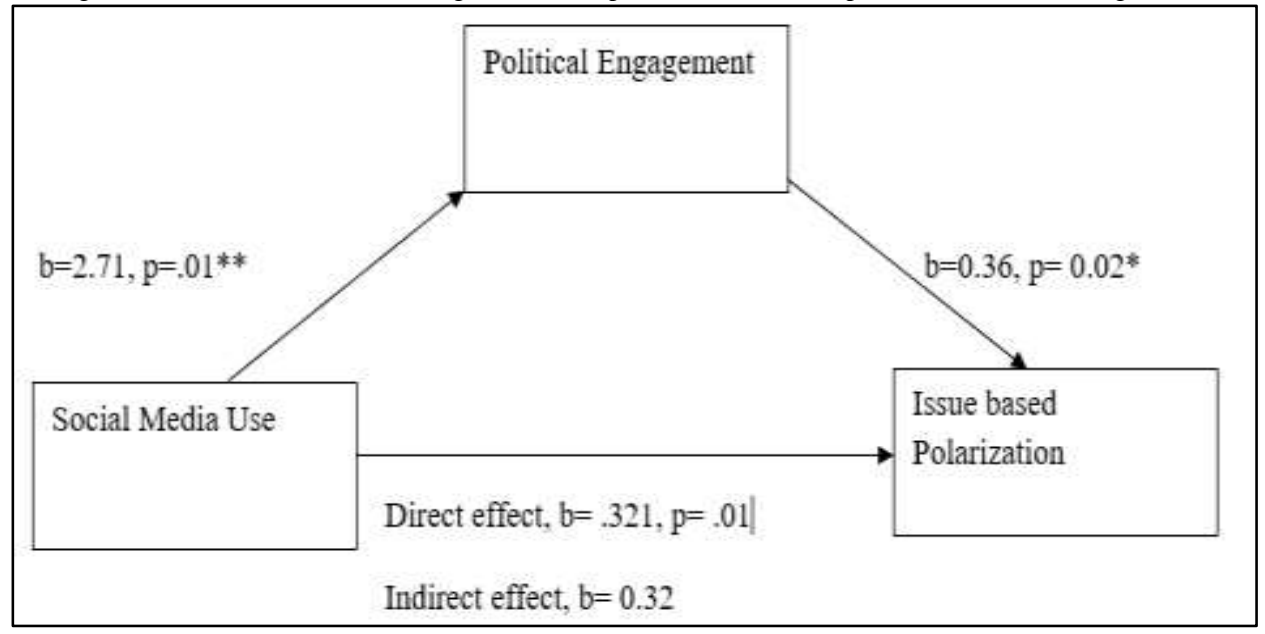

\section{Discussion}

The current research examined the association between social media and political polarization in students of private universities. The study is being conducted to examine how individuals get politically polarized and become loyal to a particular party by using social media and this relationship is tested by the mediation model. The polarization was tested by choosing political engagement as a moderator to investigate the relationship of social media with three different variables includes party-based polarization, leader based, and issue-based polarization. Political engagement is playing the role of mediator as well as the dependent variable which in results that independent variable SMU (social media use) is positively associated with the political engagement, even after controlling other variables of an individual's traits. According to the previous studies, people who are more indulge in the social media such as Facebook and Twitter are likely to have more varied networks and groups on social networking sites (Al Omoush et al., 2012; LaRose et al., 2014; Ogaji et al., 2017). The results showed that social media is highly recommended for information purposes so in that case; it is also helping in the communication sectors which helps in progressing in the field of democracy. The most important argument in this matter is described as social media provide its users to select the content which is supporting their viewpoints, and this enhances the polarization and fragmentation (Sunstein, 2001).

The results demonstrated that the political engagement of individuals through social media is completely mediating the relationship between social media use and political party-based polarization, leadership-based polarization, and issue-based polarization. The findings were explained with the consistency of the previous study which declared that media is used for informational purposes which expands their social networks, boundaries, and participating activities (Brundidge, 2010; Valenzuela et al., 2012). Some users are not much engaged in political activities and they usually avoid posting and sharing political stuff just because of the fear of offending their social networks (Rainie et al., 2012). This censorship may reduce political communication on social media which reduces opinion polarization (Habermas, 1989). It can be assumed that people who participate in political discussions on social media are highly interested and aware of political issues which are resulted in having strong opinions. This increases the polarization of their behavior and attitudes by discussing political matters with others on social media. This study focuses on the understanding of political polarization and loyalty towards a particular political party by using social media which is concluded as discussing the main impact of social media on the attitudes and behavior of people who are using it which leads to the polarization of their opinions in the matter of polarization.

\section{Conclusion}

Social media is now serving as the platform for the dissemination of political information. Individuals can get the political information easily and this information is not coming through traditional old media, it is transmitted to the audience directly from the political officials, their peers and family. Social media is now allowing people to discuss different political events with their friends as well as with those people whom they have not much strong bonding.

The term "echo chamber" is relatable to the internet which means that people get exposed to the opinions which are produced by likeminded users, but this demonstration cleared that social media provide the diverse political information from all sides. In this study, it was examined through cross-sectional research that social media which provide exposure to diverse political viewpoints of different users has a positive influence on political polarization.

\subsection{Limitations and Suggestions}

Although the present study was done with utmost input certain limitations are noteworthy. The sample was only comprised of students who belonged to a private university. The population who belonged to schools and colleges 
was not included because of cultural boundaries. If it allows then the comparison could help more in understanding the impact of social media on political polarization. Secondly, this topic holds personal opinions and viewpoints so it needed to research the broader platform on that the reason could be evaluated and analyzed.

\subsection{Future Implications of Research}

The present study imply a lot of suggestions for the researchers, practitioners, political scientists, and media practitioners in Pakistan for the understanding of this issue on a broader level. The study will help to plan serious intervention for the negative consequences. It will help to conduct workshops on the understanding of political polarization on a political and communication level so that it can help in all levels of political science. It will help in promoting the medium of disclosing and providing information on a broader level.

\section{References}

Aday, S., Farrell, H., Freelon, D., Lynch, M., Sides, J. and Dewar, M. (2013). Watching from afar: Media consumption patterns around the Arab Spring. American Behavioral Scientist, 57(7): 899-919.

Al Omoush, K. S., Yaseen, S. G. and Alma'Aitah, M. A. (2012). The impact of Arab cultural values on online social networking: The case of Facebook. Computers in Human Behavior, 28(6): 2387-99.

Bakshy, E., Messing, S. and Adamic, L. A. (2015). Exposure to ideologically diverse news and opinion on Facebook. Science, 348(6239): 1130-32.

Baldassarri, D. and Bearman, P. (2007). Dynamics of political polarization. American Sociological Review, 72(5): 784-811.

Barberá, P. (2015). Birds of the same feather tweet together: Bayesian ideal point estimation using Twitter data. Political Analysis, 23(1): 76-91.

Barberá, P., Jost, J. T., Nagler, J., Tucker, J. A. and Bonneau, R. (2015). Tweeting from left to right: Is online political communication more than an echo chamber? Psychological science, 26(10): 1531-42.

Bennett, W. L. and Segerberg, A. (2013). The logic of connective action: Digital media and the personalization of contentious politics. Cambridge University Press.

Boxell, L., Gentzkow, M. and Shapiro, J. M. (2017). Is the internet causing political polarization? Evidence from demographics (No 23258). NBER Working Papers, National Bureau of Economic Research, Inc.

Brundidge, J. (2010). Encountering "difference" in the contemporary public sphere: The contribution of the Internet to the heterogeneity of political discussion networks. Journal of Communication, 60(4): 680-700.

Cherubini, F. and Nielsen, R. K. (2016). Editorial analytics: How news media are developing and using audience data and metrics. Reuters Institute for the Study of Journalism: Oxford.

Correa, T., Hinsley, A. W. and De Zuniga, H. G. (2010). Who interacts on the Web?: The intersection of users' personality and social media use. Computers in Human Behavior, 26(2): 247-53.

Crossman, A. (2017). Understanding purposive sampling. Available: https://www.thoughtco.com/purposivesampling-3026727

Farrell, H. and Drezner, D. W. (2008). The power and politics of blogs. Public Choice, 134(1-2): 15-30.

Gentzkow, M. and Shapiro, J. M. (2011). Ideological segregation online and offline. The Quarterly Journal of Economics, 126(4): 1799-839.

Greenwood, D. J. and Levin, M. (2006). Introduction to action research: Social research for social change. SAGE publications.

Habermas, J. (1989). On society and politics: A reader. Beacon Press.

Hart, P. S. and Nisbet, E. C. (2012). Boomerang effects in science communication: How motivated reasoning and identity cues amplify opinion polarization about climate mitigation policies. Communication Research, 39(6): 701-23.

Hastorf, A. H. and Cantril, H. (1954). They saw a game: A case study. Journal of Abnormal and Social Psychology, 49(1): 129-34.

Jarral, K. (2018). Pakistan Election: the role of social media. Asia Research Institute: Available: https://theasiadialogue.com/2018/10/15/pakistan-elections-the-role-of-social-media/

LaRose, R., Connolly, R., Lee, H., Li, K. and Hales, K. D. (2014). Connection overload? A cross cultural study of the consequences of social media connection. Information Systems Management, 31(1): 59-73.

Lassen, D. S. and Brown, A. R. (2011). Twitter: The electoral connection? Social Science Computer Review, 29(4): 419-36.

Lee (2016). Impact of social media on opinion polarization in varying times. Communication and the Public, 1(1): 56-71.

Lee and Chan, J. M. (2016). Digital media activities and mode of participation in a protest campaign: A study of the Umbrella Movement. Information, Communication and Society, 19(1): 4-22.

Lee, Shin, J. and Hong, A. (2018). Does social media use really make people politically polarized? Direct and indirect effects of social media use on political polarization in South Korea. Telematics and Informatics, 35(1): 245-54.

Lelkes, Y. and Westwood, S. J. (2017). The limits of partisan prejudice. The Journal of Politics, 79(2): 485-501.

Levendusky, M. S. and Malhotra, N. (2016). (Mis) perceptions of partisan polarization in the American public. Public Opinion Quarterly, 80(S1): 378-91. 
Masih, N. and Slater, J. (2019). U.S.-style polarization has arrived in India. Modi is at the heart of the divide. The Washington Post. https://www.washingtonpost.com/world/asia_pacific/divided-families-and-tense-silencesus-style-polarization-arrives-in-india/2019/05/18/734bfdc6-5bb3-11e9-98d4-844088d135f2_story.html

Matsuno, E. (2013). Attitude extremity and party identification strength on perceived polarization (publication no. 436) Honors Thesis, University of Colorado Boulder. UC Campus Repository. https://scholar.colorado.edu/honr_theses/436

Newport, F. (2019). The impact of increased political polarization. Gallup. https://news.gallup.com/opinion/pollingmatters/268982/impact-increased-political-polarization.aspx

Neyazi, T. A. (2020). Digital propaganda, political bots and polarized politics in India. Asian Journal of Communication, 30(1): 39-57.

Ogaji, I. J., Okoyeukwu, P. C., Wanjiku, I. W., Osiro, E. A. and Ogutu, D. A. (2017). Pattern of use of social media networking by Pharmacy students of Kenyatta university, Nairobi, Kenya. Computers in Human Behavior, 66(1): 211-16.

Poushter, J., Bishop, C. and Chwe, H. (2018). Social media use continues to rise in developing countries but plateaus across developed ones. Pew Research Center. http://www.pewglobal.org/2018/06/19/socialmedia-use-continues-to-rise-indeveloping-countries-but-plateaus-across-developed-ones/

Rainie, L., Smith, A., Schlozman, K. L., Brady, H. and Verba, S. (2012). Social media and political engagement. Pew Internet and American Life Project, 19(1): 2-13.

Shin, J. and Thorson, K. (2017). Partisan selective sharing: The biased diffusion of fact-checking messages on social media. Journal of Communication, 67(2): 233-55.

Stieglitz, S. and Dang-Xuan, L., 2012. "Political communication and influence through microblogging--An empirical analysis of sentiment in Twitter messages and retweet behavior." In 2012 45th Hawaii International Conference on System Sciences. IEEE. pp. 3500-09.

Sunstein, C. R. (2001). Republic.com. Princeton University Press: NJ.

Taber, C. S. and Lodge, M. (2006). Motivated skepticism in the evaluation of political beliefs. American Journal of Political Science, 50(1): 755-69.

Tang, G. (2015). Mobilization by images: TV screen and mediated instant grievances in the Umbrella Movement. Chinese Journal of Communication, 8(4): 338-55.

Thatcher, J., Day, M. and Rahman, R. (2011). Sport and exercise Psychology. Learning Matters.

Valenzuela, S., Arriagada, A. and Scherman, A. (2012). The social media basis of youth protest behavior: The case of Chile. Journal of Communication, 62(2): 299-314.

Williams, C. B. and Gulati, G. J. (2009). Facebook grows up: An empirical assessment of its role in the 2008 congressional elections. Proceedings from Midwest Political Science Association, Chicago, 32(1): 53-70. 